\title{
Research on the Teaching Reform of Polymer Materials Foundation Course - Based on the Case Analysis Method
}

\author{
Yinjie Wang*, Jiping Liu, Jia Han, Xingyan Xu \\ School of Materials Science and Engineering, Beijing Institute of Technology, Beijing 100081, China \\ *Corresponding author: Yinjie Wang, 1632265752@qq.com
}

\begin{abstract}
In today's education and teaching reform, the traditional teaching method in the teaching of polymer materials has been gradually replaced with various new teaching methods. Among them, the case analysis method is a very effective teaching method, which has been applied to the teaching of polymer materials. Through example-based teaching, students' participation can be effectively improved, and their theoretical knowledge can be fully utilized. This would have a positive role in promoting the improvement of students' knowledge system and their learning ability. In regard to this, this article analyzes the application of case analysis in the teaching of polymer materials so as to improve its efficiency and quality.
\end{abstract}

Keywords: Polymer materials foundation course; Case analysis method; Classroom teaching; Teaching reform

Publication date: October 2021; Online publication: October 29, 2021

\section{Introduction}

In the context of today's teaching reform, the polymer materials foundation course has also changed its traditional instillation teaching method. It has begun to focus on the creation of a good learning environment and the cultivation of students' learning interest. Through practice and research, it has been found that in the teaching process of polymer materials, the reasonable application of case analysis can effectively attract students' attention, stimulate their enthusiasm to participate, and further improve the teaching effect. Therefore, in the teaching of this course, teachers should pay attention to the reasonable application of case analysis and make full use of its advantages to promote better learning and development among students.

\section{Analysis on the existing problems in the teaching of polymer materials}

With the continuous advancement of today's education and teaching reform, the teaching of polymer materials has also achieved new innovations in models and methods. However, as far as the current teaching of polymer materials is concerned, some teachers are still applying traditional teaching concepts in view of the relatively short period designated for the curriculum reform. Therefore, there are still several problems in the teaching, thus making it difficult to effectively improve the teaching efficiency and the quality of the polymer materials foundation course. The main problems are related to the teaching contents, teaching methods, and teaching evaluation. The details are as shown in Table 1. 
Table 1. Main problems in the teaching of polymer materials and their specific situations

\begin{tabular}{|c|c|}
\hline Problems & Specific situations \\
\hline Teaching contents & $\begin{array}{l}\text { The teaching contents are excessive and abstruse, and the information updates are slow. This is } \\
\text { a disadvantage for specialized talent training in electronic packaging. }\end{array}$ \\
\hline Teaching methods & $\begin{array}{l}\text { The time is limited for students to participate in lessons, such as independent research and } \\
\text { discussion, which can stimulate students' interest in learning. }\end{array}$ \\
\hline Teaching evaluation & The emphasis on final grades is excessive while students' daily performance is neglected. \\
\hline
\end{tabular}

Therefore, it is necessary to introduce new teaching models and methods in the polymer materials foundation course. In this way, the teaching reform can be further deepened, and the teaching efficiency as well as its quality can be promoted simultaneously. After many research and analysis, it has been found that applying the case analysis method to the teaching process of this course can effectively solve the above problems, stimulate students' interest in learning, and enhance their enthusiasm for learning. It also makes them actively participate in the teaching of the course, thus ensuring the teaching effect ${ }^{[1]}$. The application analysis of the case analysis method in the teaching of polymer materials is discussed below.

\section{Application analysis of the case analysis method in the teaching of polymer materials}

\subsection{Theoretical knowledge case selection}

In the teaching of polymer materials through case analysis, one of the first contents is the reasonable selection of theoretical knowledge cases. In this process, teachers need to determine the main theoretical knowledge points in the course. For key knowledge points, it is necessary for teachers to comprehensively consider the background, formation process, and purpose of the theoretical knowledge. They should then clarify the formation, development, and function of these theoretical knowledge points in order to use them as the basis for case compilation. Table 2 shows several main theories and knowledge points that can be found in specific course design cases.

Table 2. Main theories and knowledge points in specific course design cases

\begin{tabular}{|c|c|c|}
\hline Theories & Main knowledge points & Main function \\
\hline Valence bond theory & $\begin{array}{l}\text { Include the formation of covalent bonds, bond } \\
\text { type, saturation, and hybridization (including } \\
\text { SP hybridization, SP2 hybridization, and SP3 } \\
\text { hybridization). }\end{array}$ & $\begin{array}{l}\text { Helps students gain a better understanding } \\
\text { of organic matter and deepen their } \\
\text { understanding of the physical and chemical } \\
\text { properties of organic matter. }\end{array}$ \\
\hline Lewis acid-base theory & Include the concepts of Lewis acids bases. & $\begin{array}{l}\text { Helps students gain better understanding of } \\
\text { the reaction process of organic chemistry. }\end{array}$ \\
\hline Glass transition theory & $\begin{array}{l}\text { Include free volume theory, thermodynamic } \\
\text { theory, etc. }\end{array}$ & $\begin{array}{l}\text { Helps students gain an in-depth } \\
\text { understanding of several experimental } \\
\text { phenomena in glass transition. }\end{array}$ \\
\hline $\begin{array}{l}\text { Time-temperature } \\
\text { superposition principle } \\
\text { in regard to polymer } \\
\text { viscoelasticity }\end{array}$ & $\begin{array}{l}\text { The viscoelastic performance at a higher } \\
\text { temperature in a short period of time is } \\
\text { equivalent to the viscoelastic performance at a } \\
\text { lower temperature in a long period of time. }\end{array}$ & $\begin{array}{l}\text { Helps students gain an in-depth } \\
\text { understanding of the stress relaxation } \\
\text { process. }\end{array}$ \\
\hline
\end{tabular}

In the teaching process of polymer materials, through the establishment of a knowledge case library, students may have a clearer understanding of the relationship between relevant theories and their 
corresponding knowledge points. This would provide sufficient foundation for their understanding of the knowledge content. For example, after students have gained a comprehensive understanding of hybridization in the valence bond theory, they would be able to better understand the reasons for the physical properties of the cis and trans isomers in the symmetrically substituted form of olefin molecules. The saturated carbon atoms in olefin molecules are SP3 hybridized while the double-bonded carbon atoms are SP2 hybridized; thus, the two have different electronegativity, and the formation of chemical bonds also has a dipole moment. In the symmetrically substituted form of the olefin molecule, the symmetric molecule is the trans isomer, and its dipole moment is zero; while in the form of cis isomer, the two substituents are on the same side of the double bond, and the dipole moment is not zero. If the dipole moment is zero, not only van der Waals forces exist between the molecules, but also dipole-dipole interactions. Therefore, cis isomers usually have a higher boiling point compared to trans isomers ${ }^{[2]}$. In regard to polymer viscoelasticity, after students have mastered the principle of time-temperature superposition, they would be able to reach a conclusion whereby the viscoelastic energy at a higher temperature in a short period of time is equivalent to the elastic energy at a lower temperature in a long time. This would also promote students' understanding of stress relaxation, hysteresis, transformation, and mechanical loss.

\subsection{Teaching process of theoretical knowledge through case analysis}

In the process of teaching through case analysis, teachers should use relevant theoretical knowledge points in combination with corresponding cases to guide students in their preparations before classes. Teachers should also encourage students to participate during classroom teaching and make use of the case analysis with other students to learn and solve problems after their classes. Teachers can further strengthen the teaching effect achieved through the case analysis method by designing a set of teaching methods and auxiliary teaching methods. For example, teachers can share cases that correspond to the theories and knowledge points which would be discussed during the upcoming lesson with the students so that they would come prepared with questions after the preview, thus further improving their listening efficiency. During classes, teachers should provide more interactive links and time for the students as well as encourage learning interaction through questions, discussions, etc., to improve students' participation and the teaching effect. After classes, teachers should encourage their students to integrate relevant knowledge into the reality of life in order to strengthen their understanding and mastery of theoretical knowledge.

For example, in teaching viscoelasticity, teachers can teach students the theoretical knowledge and share the corresponding cases before classes, thus allowing sufficient time for them to prepare. During the actual class, teachers can then encourage their students to raise questions or share the problems that they have encountered during the preview process. Through discussions and examples given to solve these problems, the students' understanding of that topic would improve. For example, in regard to creep, students should first be guided to have a clear grasp of the knowledge points in combination with their practical applications. As the topic is very practical, this property can reflect the size and stability of a material. Therefore, teachers should use examples to help students understand that the engineering plastics which are selected in the production and manufacturing of mechanical parts must be small and polytetrafluoroethylene (PTFE) has great creep. With this property, this material can be used for water pipes. In order to avoid the intermolecular slippage caused by creep and the irreversible deformation, its rubber needs to be produced by vulcanization cross-linking.

Through the combination of these theoretical knowledge and practical applications, students would not only master the knowledge points well but also apply these theoretical knowledge points to actual production and life. Hence, the knowledge learned can be used reasonably, and the situational gap of textbook knowledge and practical application can be avoided. This is extremely beneficial to the improvement of the teaching effect of the course and the development of the students. 


\subsection{Teaching evaluation of theoretical knowledge through case analysis}

In consideration of the regulations in the teaching objectives of the new curriculum and the actual requirements of electronic packaging talents, teachers should use relevant theoretical knowledge and corresponding cases as the basis in the teaching of polymer materials through case analysis. Teachers should create an evaluation system for teaching effects and the training of students' ability so that the students are able to fully gauge the specific teaching effects gained in teaching. They should then form a set of effective teaching evaluation methods.

In the teaching evaluation process, teachers should pay more attention to students' classroom performance and change the original examination system from $75 \%$ of the final exam's score and $25 \%$ of classroom performance to $70 \%$ of the final exam's score and $30 \%$ of classroom performance. During normal lessons, teachers should grade the learning of each student for each teaching case and include those grades into the final evaluation. In this way, students would be more proactive in their learning and research for each teaching case, thereby stimulating their enthusiasm for learning. This would play a positive role in promoting the teaching quality and the development of students.

\subsection{Case analysis in applied technology knowledge}

In the teaching of polymer materials, the main purpose of case analysis in applied technology knowledge is to cultivate students' practical skills and theoretical knowledge application ability. By encouraging students to learn and solve practical problems through relevant theoretical knowledge, they would eventually be able to truly apply what they have learned in the future. Based on this, in the teaching of polymer materials through case analysis, teachers should establish a reasonable design for the case analysis method in line with the theoretical knowledge learned by the students and the requirements in practical application so as to ensure the correct application of technical knowledge.

For example, teachers should first divide the students into groups. By combining theoretical knowledge and actual needs, they should then encourage the students to conduct a research on the performance, current situation, and problems of epoxy resin used in electronic packaging. With relevant knowledge learned in the past, the students should then propose preliminary solutions to the corresponding problems and then perform a write-up based on all this information to form a complete knowledge case library ${ }^{[3]}$. Finally, teachers should encourage each group of students to present their papers in the form of PowerPoint. Table 3 shows several major thesis topics in the teaching of polymer materials for a university's electronic packaging specialty.

Table 3. Major thesis topics in the teaching of polymer materials for electronic packaging specialty

\begin{tabular}{cl}
\hline Group & \multicolumn{1}{c}{ Thesis topics } \\
\hline 1 & Acrylic modified epoxy resin paper \\
\cline { 2 - 2 } 3 & Effect of polyether grafted polysiloxane copolymer on the properties of epoxy resin \\
4 & Application of epoxy resin in electronic packaging \\
5 & Research on toughening modification method and creep resistance of epoxy resin \\
6 & Modification and application of epoxy resin in electronic packaging \\
7 & Epoxy resin structure changes properties \\
\hline
\end{tabular}

By completing the above application technology knowledge cases, students can realize the organic combination of theory and practice while learning. It also lays a good foundation for future learning and work in the field of polymer materials. 


\section{Conclusion}

In conclusion, the case analysis method is an extremely effective teaching method in the teaching of polymer materials. Therefore, in teaching, teachers should reasonably apply this method to improve the teaching effect and promote good learning and development among students.

\section{Disclosure statement}

The authors declare that there is no conflict of interest.

\section{References}

[1] Pan G, Xing R, Zhang B, 2021, Exploration and Practice of Teaching Reform of "Polymer Materials" Course. Heilongjiang Education (Higher Education Research and Evaluation), (05): 31-32.

[2] Liang W, Fu L, Chen L, 2020, Exploration on Teaching Reform of Fundamentals of Material Science for Polymer Materials Specialty. Guangdong Chemical Industry, (01): 161.

[3] Yin Y, 2017, Exploration and Practice of Teaching Reform of Fundamentals of Polymer Materials. Guangzhou Chemical Industry, (19): 153-154. 